\title{
Spatial segregation of Darwinula stevensoni (Crustacea: Ostracoda) genotypes in lentic and lotic habitats of Northern Italy
}

\author{
Valeria ROSSI*, Carlo BELLAVERE, Giorgio BENASSI, Andrea GANDOLFI, Eletta B.A. TODESCHI \\ and Paolo MENOZZI
}

Department of Environmental Sciences, University of Parma, Parco Area delle Scienze 11/A, I-43100 Parma (Italy)

*e-mail corresponding author: valeria.rossi@unipr.it

\begin{abstract}
The clonal structure of apomictic populations of Darwinula stevensoni from Northern Italy lacustrine and riverine habitats has been analysed by allozyme electrophoresis. Thirty two sites were sampled and a total of 748 individuals were analysed. Only one polymorphic locus, Gpi, turned out to have enough variation to be informative. Two thirds of all individuals were homozygous for the most frequent allele but the frequency of this genotype was significantly lower in rivers (16\%) than in lakes (92\%). As a consequence homozygous clonal females are dominant in lacustrine habitats while heterozygous clonal females are dominant in riverine ones. Differences in genetic structure between habitats were observed even at distances of a few meters. Allele and genotype frequencies are significantly different between Lake Montorfano and its outflow (River Seveso) and between Mantova lakes and their two tributaries, the River Mincio and Corniano Channel. The former is also the outflow of Lake Garda. By laboratory experiments, we previously reported difference between genotypes: homozygous females from Mantova lakes show significantly lower starvation tolerance than heterozygous females from River Mincio. We discuss the hypothesis that habitat segregation is related to this difference. Riverine females should be better adapted to low productivity ecosystems than lacustrine ones.
\end{abstract}

Key words: apomictic parthenogenesis, clonal diversity, habitat specialisation

\section{INTRODUCTION}

As stressed by Wuethrich (1998) after decades of theorising about the evolution of sex, we are at last beginning to test hypotheses on the costs and benefits of sexual and asexual reproduction (Butlin 2002). In the last 20 years, the classical position that parthenogenetic organisms are genetically uniform or less variable than amphimictic ones, due to the benefits of recombination in generating diversity and in purging the genome of harmful mutations, lost the almost unanimous support previously enjoyed (Bell 1982; Stearns 1987). Parthenogenesis is now not seen as an evolutionary dead end given the evidence that has been accumulated on genetic variability among clones clearly sufficient in most cases for sustaining a lineage for long periods on an evolutionary time scale (Judson \& Normark 1996; Normark et al. 2003).

Among non-marine ostracod species, sex ratio is female biased and most species or populations are putative asexuals (Chaplin et al. 1994). Many extant geographic parthenogens are much more widespread than their sexual relatives, present very high clonal diversity and specialised ecotypes capable of existence and coexistence under a wide variety of environmental conditions (Butlin et al. 1998; Rossi et al. 1998; Cywinska \& Hebert 2002). In Cypricercus, Heterocypris (Cyprinotus) and Eucypris, the recruitment of new clones is probably obtained through interbreeding among congeneric species or close sexual relatives (Turgeon \&
Hebert 1994, 1995; Rossi et al. 1998; Schön et al. 2000).

In the super-family Darwinuloidea fossil record goes back at least 200 Myr without evidence of sexuality (Martens et al. 2003) and all species are obligate parthenogens: this seems to make hybridisation among congeneric species or with close sexual relatives impossible. Darwinula stevensoni is an obligate ancient parthenogenetic non-marine ostracod that has been proposed as a typical example of an "ancient asexual scandal" (Wuethrich 1998; Martens 1998). This benthic detritivorous species is geographically widespread and is typically found in the littoral, shallow limnic zone of many permanent lentic habitats. Its presence in running water seems to be sporadic even if Brady \& Norman (1889) reported its widespread riverine distribution (see also Mezquita et al. 1999). Schön et al. (1998) and Gandolfi et al. (2001a) reported very low genetic variability for this species in different population in Europe and South Africa using DNA sequences of mitochondrial COI and nuclear ITS1 regions.

The work presented here is part of a wider study of the genetic variability of European $D$. stevensoni populations carried out by allozymes. On a total of 9 loci scored, only Gpi locus was polymorphic (Rossi et al. 2004). All 33 populations analysed, from Finland to Israel, share the most common allele carried by $91 \%$ of all individuals while the most common genotype (homozygous for the most common allele) is carried by $83 \%$ of the almost 2000 individuals that were analysed. 


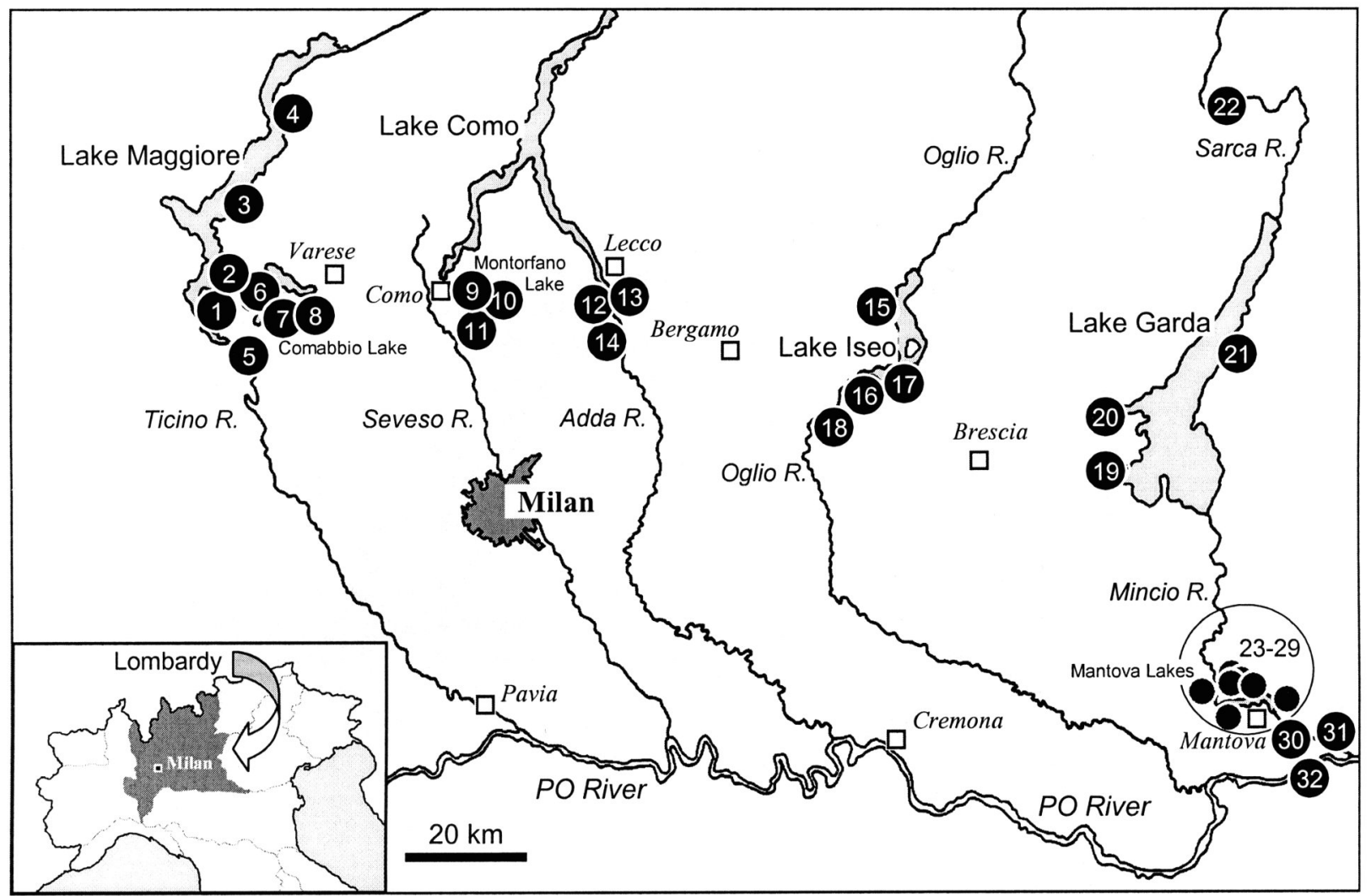

Fig. 1. Locations of the 32 sites representing lacustrine habitats and their inflow and/or outflow sampled in Lombardy (Northern Italy). Lake Maggiore (stations: 1, Angera; 2, Brebbia; 3, Cerro; 4, Maccagno) and its outflow, River Ticino (station 5, Sesto Calende). Lake Comabbio (stations: 6, Varano Borghi; 7, Ternate) and its outflow, Brabbia Channel (station 8, Cazzago Brabbia). Lake Montorfano (stations: 9, Montorfano Lido; 10, Lompo) and its outflow, River Seveso (station 11, Montorfano). Lake Como (stations: 12, Orsenigo; 13, Garlate) and its outflow, River Adda (station 14, Olginate). Lake Iseo (stations: 15, Rivalta di Solto; 16, Paratico; 17, Torbiere di Iseo) and its outflow, River Oglio (station 18, Palazzolo S/O). Lake Garda (stations: 19, Padenghe; 20, Salò; 21, Castelletto di Brenzone), its inflow, River Sarca (station 22, Ragoli) and its outflow, River Mincio (station 23, Rivalta). Mantova lakes (stations: 24, Angeli; 25, Porta Molina; 26, Porto Catena (see Fig. 2)), its inflows, River Mincio (station 23, Rivalta) and Corniano Channel (stations: 27, Botteghino; 28, Casetta; 29, Cava, see Fig. 3) and its outflow, River Mincio (stations: 30, Formigosa; 31, Governolo). River Po (station: 32, San Benedetto Po).

Local genetic differentiation among populations and genetic polymorphism may result from stochastic events or from temporal and spatial habitat selection. Microgeographical variations in allele and genotype frequencies were described in different aquatic parthenogenetic organisms (Weider 1985; Weider \& Hebert 1987; De Meester 1996; Ross et al. 1996; Anlauf \& Neumann 1997). Assuming that parthenogenesis in D. stevensoni is apomictic, mutation and gene conversion (Gandolfi et al. 2003) could be the actual sources of genetic differentiation then modulated by local selection of clones.

To test this hypothesis, we analysed the fine-grained genetic heterogeneity of $D$. stevensoni. Here we report details about the analysis of populations from some of the main lacustrine and riverine habitats in Lombardy (Northern Italy). In particular, the spatial differentiation of genetic structure was evaluated at local geographic scale in the area of Parco del Mincio (Mantova) where, a seasonal analysis of clonal variability was also performed.

\section{MATERIAL AND METHODS}

Sampling was carried out between April 1995 and November 1997 from the sediment-water interface of the littoral area of 32 sites representing some of the main lacustrine habitats and their inflow and/or outflow in Lombardy (Northern Italy) (Fig. 1). In the south-eastern part of Lombardy, in the area of the regional park "Parco del Mincio" (www.parks.it/parco.mincio), a finer spatial and seasonal analysis was performed. In this area three sampling stations were chosen along the River Mincio (Rivalta, Governolo and Formigosa) that eventually flows into the River Po. The River Mincio belongs to the fluvial system that includes the River Sarca, the Lake Garda and the Mantova lakes (Lago Superiore, Lago di Mezzo, Lago Inferiore), a wetland area along the lower course of the River Mincio. Along the River Mincio, Rivalta station is upstream from the complex of Mantova lakes, Governolo and Formigosa stations are between Mantova lakes and the River Po (Fig. 1). The 


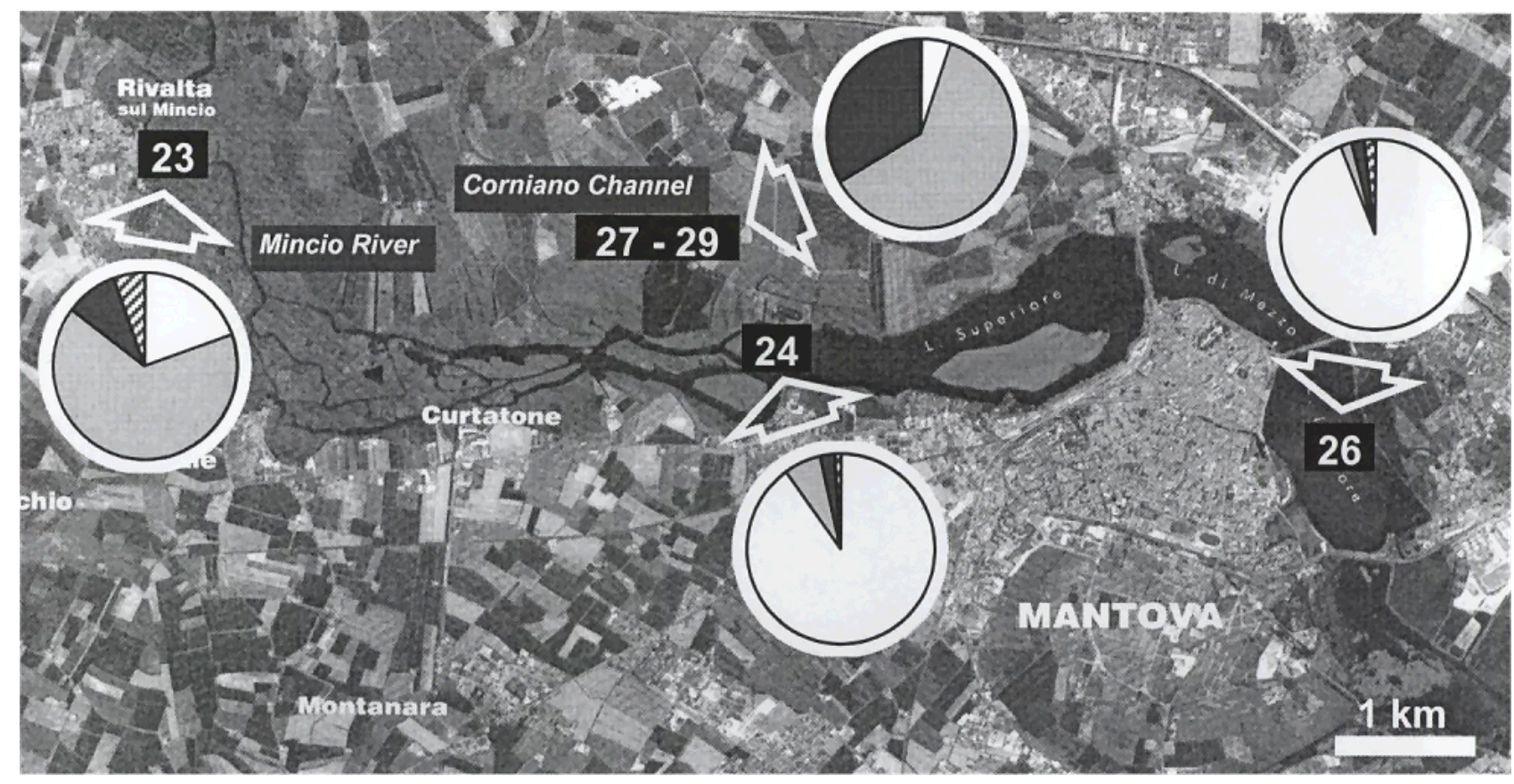

Fig. 2. Geographic distribution of all seasons genotype frequencies in River Mincio (station 23, Rivalta ), Corniano Channel (stations: 27, Botteghino; 28, Casetta; 29, Cava), Lake Mantova Superiore (station 24, Angeli) and Lake Mantova Inferiore (station 26, Porto Catena). Genotypes at Gpi locus: 22 in white; 23 in grey; 24 in black; others in hatched (see table 1).

River Po was sampled in the locality of San Benedetto Po (Fig. 1). Three sampling stations were chosen in the Mantova lakes complex: Angeli (Lago Superiore), Porta Molina (Lago di Mezzo), Porto Catena (Lago Inferiore) (Fig. 2). Three sampling stations were chosen along the Corniano Channel, a $3 \mathrm{~km}$ long channel tributary of Lago Superiore: Botteghino, Casetta and Cava (Fig. 3). These three stations were, respectively, about 3,2 and 1 $\mathrm{km}$ far from the lake.

In lotic habitats sampling was generally performed in suitable sites as close as possible to the inflow-outflow. An aquatic net $(24 \times 12 \mathrm{~cm}$, mesh $126 \mu \mathrm{m})$ was used to sieve superficial sediments. Samples were hand sorted under a stereo microscope and all live animals separated and maintained at $16{ }^{\circ} \mathrm{C}$ in Evian spring water or frozen at $-80^{\circ} \mathrm{C}$ until electrophoretic analysis.

Only two loci, Gpi (E.C.5.3.1.9) and Pgm (E.C.2.7.5.1), that were previously shown to be consistently scorable, were used (Rossi et al. 2004). The number of alleles per locus and the number of multilocus genotypes per sample were calculated from the scores obtained from individual organisms. Alleles were scored using numbers reflecting their increasing electrophoretic anodal mobility, 1 being the slowest. Genotypes are designed by a couple of numbers according to their homozygous (a couple of equal alleles) or heterozygous (a couple of different alleles) status. Allele and genotypic frequencies were compared by $\chi^{2}$.

Statistical analysis was carried out using Biosys1 package (Swofford \& Selander 1981) and SPSS statistical package.

\section{RESULTS}

No D. stevensoni was found in samples from Lake Maggiore, River Ticino, Lake Como, River Adda, Lake Iseo, River Oglio, River Sarca, and River Po.

We only found females; they were ovigerous in spring samples, while in autumn, samples were made up of juveniles or adult females without eggs. A total of 748 individuals were analysed by electrophoresis, 716 showed activity at, at least, one of the two loci. Only one allele was found at Pgm locus and four alleles were found at the Gpi locus. Three specimens, one from Mincio and two from Seveso riverine populations, showed two electrophoretic bands. In the case of dimeric enzymes such as Gpi this is suggestive of a heterozygous individual for a null allele and, in our case, of a heterozygous for alleles null and 3. Three more specimens showed activity at Pgm locus but did not show any activity at Gpi locus: they were considered homozygous for the null allele (Tab. 1). The only polymorphic locus, Gpi, was used for describing the clonal (dilocus genotypes) structure of $D$. stevensoni. Due to the low number of sampled individuals in the Brabbia Channel $(\mathrm{N}=2)$, in summer 95 sample from Lake Comabbio (Varano Borghi station $\mathrm{N}=6$ ) and in autumnal samples from Mantova Inferiore (Porto Catena station $\mathrm{N}=5$ ) and Corniano Channel (Cava station $\mathrm{N}=5$ ), these sites were excluded from further analysis.

Allele 2 was the most frequent, it was present in all sites with frequencies between 52\% (Corniano Channel) and $100 \%$ (Lake Garda) (Tab. 1). 


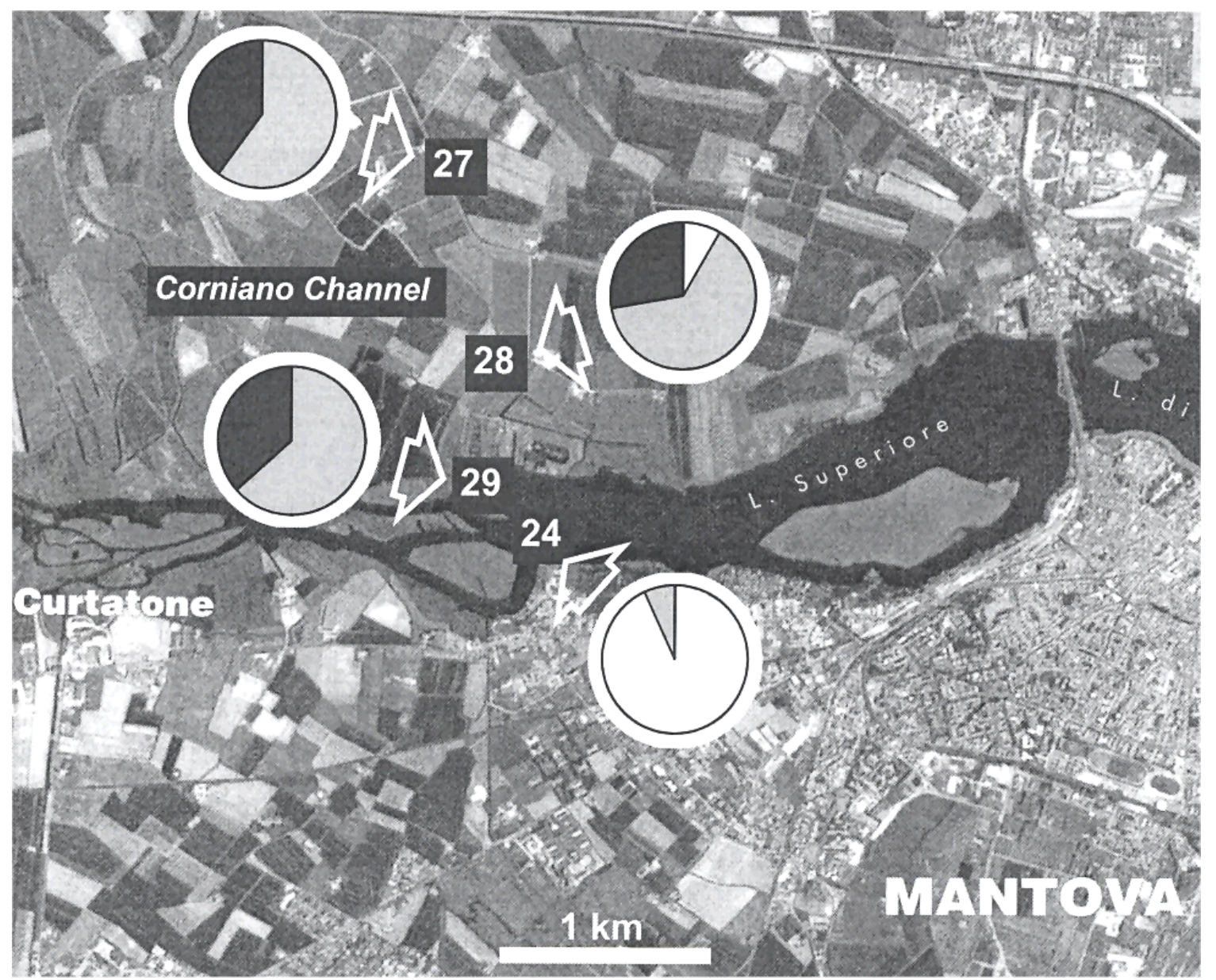

Fig. 3. Geographic distribution of spring genotype frequencies along the Corniano Channel (stations: 27, Botteghino; 28, Casetta; 29, Cava) and in Lake Mantova Superiore (station 24, Angeli). Genotypes at Gpi locus: 22 in white; 23 in grey; 24 in black (see table 1).

Tab. 1. For each site (lacustrine $=\mathrm{L}$, riverine $=\mathrm{R}$ ), sampling station, sampling season (spring=S, autumn=A), total number of individuals analysed $(\mathrm{N})$ and number of each genotype (electrophoretic phenotypes) at Gpi locus detected in D. stevensoni are reported. Homozygotes (00) and heterozygotes (03) for null allele are included (see Results). Clonal diversity (H) and clonal dominance (D) indexes are reported.

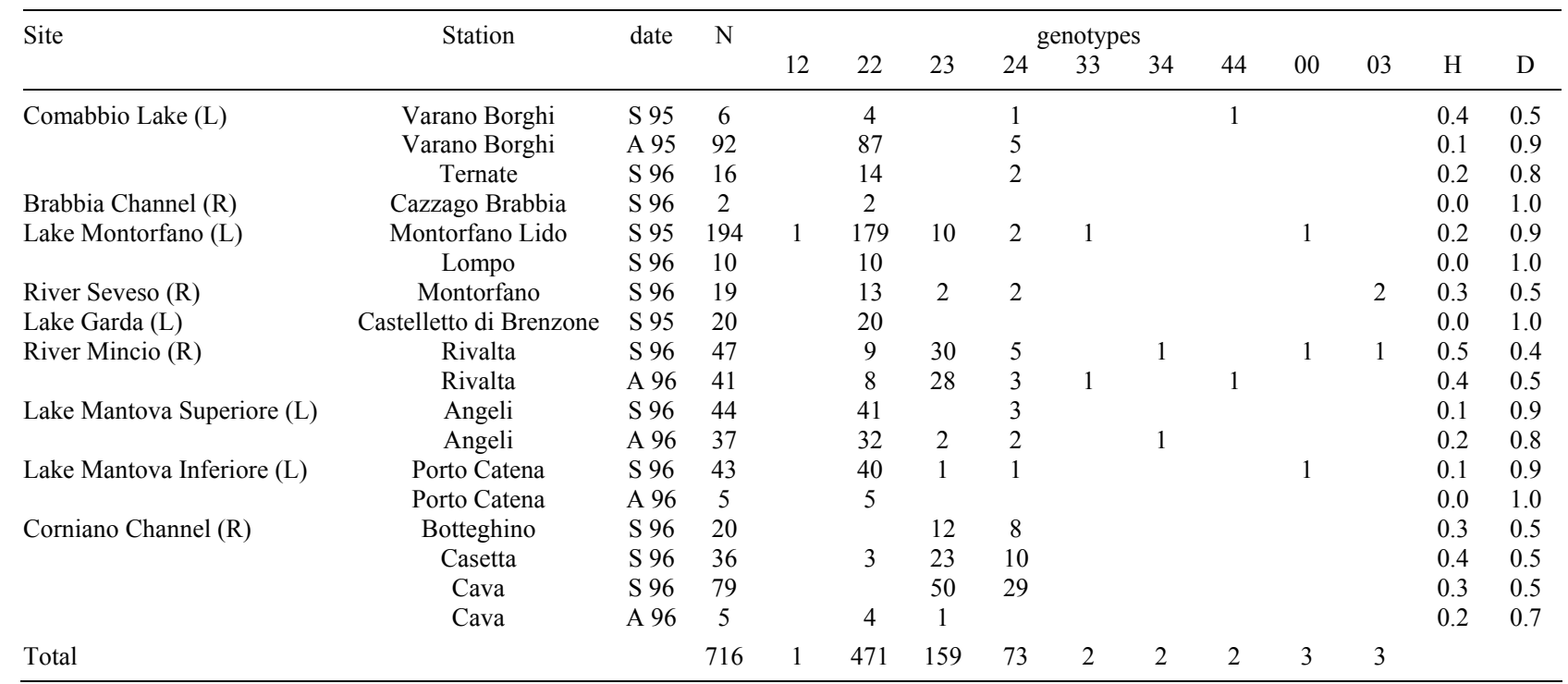


Considering only populations with $\mathrm{N}$ equal or greater than 10, allele 3 and 4 were present in almost all samples but their frequencies were higher in riverine (between 30 and 36\% for allele 3 and between 6 and $17 \%$ for allele 4) than in lacustrine habitats, where the frequencies of alleles 3 and 4 varied from 0 to $2 \%$ and $4 \%$, respectively. Allele 1 was only found in Lake Montorfano.

Significant differences were observed in allele frequencies between Montorfano Lake and its outflow River Seveso $\left(\chi^{2}=34.04, \mathrm{df}=4\right.$ ( 5 alleles $\times 2$ habitats $), p$ $<0,001)$.

In the area of Parco del Mincio, allele frequencies were significantly different among populations $\left(\chi^{2}=214.30, \mathrm{df}=12\right.$ ( 4 alleles $\times 5$ sites $\left.), p<0.001\right)$ : allele frequencies were not significantly different among lacustrine populations (Lake Garda, Lago Superiore and Lago Inferiore) $\left(\chi^{2}=8.13, \mathrm{df}=6\right.$ ( 4 alleles $\times 3$ sites $)$, $p=0.149$ ) but were significantly different between River Mincio and Corniano Channel populations $\left(\chi^{2}=15.25\right.$, $\mathrm{df}=3$ ( 4 alleles $\times 2$ sites), $p=0.0016)$. Differences in allele frequencies between Mincio and Corniano were probably related to the presence of a null allele in the Mincio population and to a higher frequency of allele 4 in Corniano than in Mincio. Seasonal differences in allele frequencies were not significant either in River Mincio $\left(\chi^{2}=2.71, \mathrm{df}=3\right.$ ( 4 alleles $\times 2$ seasons $\left.), p=0.439\right)$ or in Mantova Superiore Lake $\left(\chi^{2}=3.71, \mathrm{df}=2\right.$ (3 alleles $\times 2$ seasons $), p=0.157)$. Differences in allele frequencies were not significant among spring samples collected along the Corniano Channel transect $\left(\chi^{2}=0.961, \mathrm{df}=4\right.$ (3 alleles $\times 3$ sites), $p=0.916$ ).

In general, homozygotes for allele 2 were the most frequent genotype $(66 \%)$. In running water, the frequency of homozygotes $(16 \%)$ was significantly lower than in lakes $(92 \%)\left(\chi^{2}=466.40, \mathrm{df}=1, p<0.0001\right)$. In rivers, heterozygotes were the most frequent genotypes (heterozygotes between alleles 2 and $3(59 \%)$ and between alleles 2 and $4(23 \%))$.

A total of nine genotypes were identified: eight were detected in River Mincio, six in Lake Montorfano, four in River Seveso and three in Corniano Channel (Tab. 1). Clonal diversity is higher in riverine habitats $(0.3$ in River Seveso and 0.5 in River Mincio) than in lacustrine habitats ( 0.1 in all polyclonal sites) where dominance index is between 0.9 and 1.0 (Tab. 1).

Genotype frequencies were significantly different among sites $\left(\chi^{2}=585.72, \mathrm{df}=56\right.$ ( 9 genotypes $\times 8$ sites $), p$ $<0.0001)$ : genotype frequencies were significantly different among riverine sites $\left(\chi^{2}=92.98, \mathrm{df}=14\right.$ (8 genotypes $\times 3$ sites $), p<0.0001)$ but differences were non significant among lacustrine sites $\left(\chi^{2}=28.31, d f=24 \quad(7\right.$ genotypes $\mathrm{x} 5$ sites), $p=0.247$ ).

In Lake Comabbio no significant differences in genotype frequencies were observed between spring and autumn samples $\left(\chi^{2}=6.20, \mathrm{df}=2(3\right.$ genotypes $\times 2$ seasons), $p=0.045)$. Significant differences were observed in genotype frequencies between Lake Montorfano and its outflow $\left(\chi^{2}=32.73, \mathrm{df}=6(7\right.$ genotypes $\times 2$ habitats $), p$ $<0.001)$.

In the area of Parco del Mincio, genotype frequencies were significantly different among sites $\left(\chi^{2}=290.42\right.$, $\mathrm{df}=28$ ( 8 genotypes $\times 5$ sites $), p<0.001)$. In figure 2 the small scale geographical distribution of genotype frequency in River Mincio, Corniano Channel and Mantova Lakes is reported. Genotype frequencies were not different within lacustrine habitats $\left(\chi^{2}=5.79, \mathrm{df}=8 \quad(5\right.$ genotypes $\times 3$ habitats), $p=0.671)$ but were significantly different within riverine habitats $\left(\chi^{2}=179.09, \mathrm{df}=14(8\right.$ genotypes $\times 3$ habitats), $p<0.001)$. This result is probably due to the further decrease of homozygous 22 genotype in the Corniano Channel (5\%) and to the highest frequencies of heterozygous 34 genotype in this habitat. In figure 3 the geographical distribution of genotype frequency along the Corniano Channel and in Lake Mantova Superiore is reported. Differences in genotype frequencies were not significant within habitat in different seasons: River Mincio $\left(\chi^{2}=2.71, \mathrm{df}=3\right.$, $p=0.439)$ and Lake Mantova Superiore $\left(\chi^{2}=3.71, \mathrm{df}=2\right.$, $p=0.157)$ as well as among spring samples collected along Corniano Channel transect $\left(\chi^{2}=0.74, \mathrm{df}=2\right.$, $p=0.692$ ).

\section{DISCUSSION}

In spite of the general low genetic variability observed in European D. stevensoni populations (Schön et al. 1998; Gandolfi et al. 2001a; Rossi et al. 2004), at a local scale the species shows a relatively high number of genotypes per population. In fact, on the basis of only one polymorphic marker, 5 different alleles and up to 8 different dilocus genotypes were found in the Mincio population. This number is far from the maximum clonal variability observed in others parthenogenetic species such as Cypridopsis vidua and Heterocypris incongruens in which 24 and 35 clones were detected, respectively, in a single population, (Havel \& Hebert 1989; Havel \& Heber 1993; Rossi et al. 1998; Cywinska \& Hebert 2002). Clonal (dilocus genotypes) variability in local populations of $D$. stevensoni was similar to what reported for non marine parthenogenetic ostracod species and in aquatic asexual taxa where, in general, a single population is made up of up to five clones (Rossi et al. 1998; Cywinska \& Hebert 2002). In populations from Northern Italy we found the highest clonal diversity in Europe (Rossi et al. 2004).

All populations analysed share the most common allele (allele 2) that is the most common one in Europe. The most common genotype (homozygous for the allele 2 ) is carried by $66 \%$ of the individuals that were analysed and is recorded in all populations with the exception of 2 samples from Corniano Channel. Under this scenario of low genetic variability and low clonal diversity, differences in allele and genotype frequencies 
among populations of lentic and lotic habitats in Lombardy represent an intriguing result.

A fine-grained analysis of $D$. stevensoni clonal structure reveals small scale heterogeneity that could maintain genetic variability in this ancient asexual species. Heterozygous genotypes, rare in Italian as well as in other European lacustrie habitats, were dominant in the riverine populations we have found in Lombardy. This area is the most intensely sampled for riverine $D$. stevensoni whose reports from lotic habitats are relatively rare in literature. In fact, according to Ranta (1979), this species "seems to avoid running water". No difference in allele and genotype frequency is observed among lacustrine populations, even between the most geographically distant sites such as Comabbio and Mantova but differences between riverine and lacustrine habitats are detected at very small scale. Few meters separated the lake sampling station of Montorfano Lido and the Montorfano outflow (River Seveso) station. Along the Corniano Channel transect, Cava station is about $1 \mathrm{~km}$ far from Angeli station in Lake Mantova Superiore (Fig. 3).

Divergence in allele and genotype frequencies between populations from the Mantova Lakes and their tributaries and from Lake Montorfano and its outflow should indicate evidence of migrations, drift or selection.

Clumped distribution, clonal reproduction and low mobility of $D$. stevensoni might explain spatial segregation of different genotypes. Seasonal stability of allele and genotype frequencies are consistent with the long biological cycle of $D$. stevensoni but we have to stress that no females were found in November 1997 and in spring 1998 in Mantova lakes and River Mincio stations while further sampling in the spring of 1999 were fruitful (Rossi et al. 2002). As mean generation time is greater then 1 year and resting eggs are, unlike in most freshwater ostracods, not known in Darwinula we may exclude that this result is due to temporary population. We assume that small scale migration occurs in this species but the dominance of lacustrine populations by the homozygous genotype seems not related to stochastic events or passive dispersal. Allele and genotype frequencies are significantly different between Lake Garda and its outflow, the River Mincio, but do not differ between Lake Garda and Mantova lakes, two lacustrine habitats connected by the River Mincio. Differences between Lake Mantova Superiore and River Mincio, were observed in different seasons and different years.

Local genetic differentiation among populations and genetic polymorphism may result from spatial habitat selection. In the sediment feeder Tubifex tubifex a significant heterogeneity of allele and genotype distribution between shallow waters and lakes is described by Anlauf \& Neumann (1997). According to these authors microhabitat variations may determine a temporal shift in allele frequencies and different sensitivity of geno- types to oxygen depletion may determine the habitat segregation of different genotypes. In Daphnia pulex Weider (1985) and Weider \& Hebert (1987) described microgeographic genetic heterogeneity due to differences in low-oxygen and salinity tolerance among different clones. Moreover, different adaptation value of different Gpi genotypes has been found in several organisms (Patarnello \& Battaglia 1992; Gaffney 1994; Beaumont \& Toro 1996; Tatara et al. 1999). In Daphnia pulicaria an increase in the frequency of homozygotes at Gpi locus was associated with decreasing dissolved oxygen (Ross et al. 1996). On the other hand, if we accept apomictic parthenogenesis for D. stevensoni, Gpi can be considered as a genomic marker tightly linked to any other that has a selective advantage.

Our hypothesis is that riverine females are best adapted to low productivity habitats than lacustrine females. We have described a very high tolerance of both homozygous and heterozygous genotypes from lacustrine and riverine habitats to conductivity variation and to long-term hypoxia (Gandolfi et al. 2001c; Rossi et al. 2002). Females from lotic habitats have a smaller clutch size and lower hatching percentage than females from lentic habitats (Gandolfi et al. 2001b). The reproductive season is delayed and shorter in females from lotic than from lentic habitats. Moreover, the mean number of respiratory beat per minute (Bpm), a proxy of respiration rate and, hence, of metabolic rate, is lower in females from river than in females from lake (Rossi et al. 2002). The main difference observed between females from lakes and rivers is in starvation tolerance: homozygous females from Mantova lakes show significantly lower tolerance than heterozygous females from River Mincio (Rossi et al. 2002). Assuming that river sediments are a more variable and poorer source of organic matter than lake ones, we can consider food availability as a selection factor that allows spatial segregation of lacustrine and riverine genotypes. In Daphnia, mean appendage beat rate was reduced in organisms adapted to low levels of food (Lampert \& Brendelberger 1996). In Drosophila, starvation resistance can arise from selection regimes characterised by low predictable food source and lines selected for starvation show a lower specific metabolic rate, slower developmental time and lower viability (Hoffmann \& Parson 1989; Chippindale et al. 1996; Harsham et al. 1999).

Heterozygote excess, observed in riverine populations might be due to heterosis. In fact, while in lake habitats the dominance of a single homozygous genotype is reported (low genetic diversity, high dominance index), in riverine habitats the frequencies of heterozygous genotypes is the source of higher genetic equitability and diversity. Lacustrine and river populations are ecologically specialised as they suit to particular habitats and, respectively, show characteristics that limit their ability to exploit other environment that one's own. This seems non negligible element in evaluating evolu- 
tionary ability of $D$. stevensoni. Such an habitat specialisation is an important cause of biological diversity arisen from differences in physiological traits that affect resource and habitat use.

Clonal diversity in parthenogenetic apomictic taxa is a result of in situ diversification or is a consequence of the derivation of local population from a diverse pool of colonists (Cywinska \& Hebert 2002). Data on mitochondrial and nuclear variation and on clonal distribution in Europe (Schön et al. 1998; Gandolfi et al. 2001a; Rossi et al. 2004) seem to rule out the possibility that local populations of $D$. stevensoni derive from a diverse pool of colonists. Actually, none or very few private alleles or genotypes are found in lacustrine and riverine populations. Local polyphyly is as well excluded, as modern members of Darwinulidae are widely reported as obligate ancient parthenogens, and, in any case, no other species of this family was recorded in the sampled sites or in Northern Italy (Ghetti \& McKenzie 1981). Local divergence via mutation as well as recombination, due to mechanisms such as gene conversion and mitotic crossing over, as suggested in D. stevensoni (Gandolfi et al. 2001a; Gandolfi et al. 2003), seems a more realistic hypothesis. The actual few different clones described in Northern Italy, as well as in other European D. stevensoni populations, are genetically very similar and their differentiation seems due to mutational events. This is quite consistent with the populations having a single homozygous clone (22) from which rarest heterozygous clones are derived by mutation. The presence of alternative homozygotes at Gpi locus found in Comabbio, Montorfano and Mincio populations could be due to recurrent mutation. We can hypothesise that mutational diversification and mitotic recombination events coupled with ecological and physiological differences observed among clones and habitat selection could originate and maintain the actual clonal structure in $D$. stevensoni.

\section{ACKNOWLEDGMENTS}

We would like to dedicate this work to the memory of K.G. McKenzie. We would like to thank C. Belis, F. Briano, G. Gentile, P. Monciardini, P. Pospisil, A. Tommasi and M. Troggio for assistance in sampling and laboratory work. This research was supported by the EU Network "Evolutionary ecology of reproductive modes in non-marine Ostracoda" of the Human Capital and Mobility Program (contract no. CHRXCT930253) and by the Italian Ministero dell'Università e della Ricerca Scientifica (COFIN 99 and FIL 2001).

\section{REFERENCES}

Anlauf, A. \& D. Neumann. 1997. The genetic variability of Tubifex tubifex (Mueller) in 20 populations and its relation to habitat type. Arch. Hydrobiol., 139: 145-162.

Beaumont, A.R. \& J.E. Toro. 1996. Allozyme genetics of Mytilus edulis subjected to copper and nutritive stress. $J$. Mar. Biol. Assoc. UK, 76: 1061-1071.
Bell, G. 1982. The masterpiece of nature: the evolution and genetics of sexuality. Croom Helm, London.

Brady, G. \& A.N. Norman. 1889. A monograph of the marine and freshwater Ostracoda of the North Atlantic and of North-Western Europe. Section I: Podocopa. Scientific Transactions of the Royal Dublin Society, series 2, 4: 63270.

Butlin, R.K. 2002. The cost and benefit of sex: new insights from old asexual lineages. Nature Rev. Genet., 3: 311-317.

Butlin, R.K., I. Schön \& K. Martens. 1998. Asexual reproduction in non marine ostracods. Heredity, 81: 473-480.

Chaplin J. A., J. E. Havel \& P.D.N. Hebert. 1994. Sex and ostracods. Trends Ecol. Evol., 9: 435-439.

Chippindale, A.K., T.J. Chu \& M.R. Rose. 1996. Complex trade-offs and the evolution of starvation resistance in Drosophila melanogaster. Evolution, 50: 753-766.

Cywinska, A. \& P.D.N. Hebert. 2002. Origins of clonal diversity in the hypervariable asexual ostracode Cypridopsis vidua. J. Evol. Biol., 15: 134-145.

De Meester, L. 1996. Local genetic differentiation and adaptation in freshwater zooplankton populations: patterns and processes. Ecoscience, 3: 385-399.

Gaffney, P.M. 1994. Heterosis and heterozygote deficiencies in marine bivalves: more light? In: A.R. Beaumont (Ed.), Genetics and evolution of aquatic organisms. Chapman \& Hall, London: 146-153.

Gandolfi, A., P. Bonilauri, V. Rossi \& P. Menozzi. 2001a. Intraindividual and intraspecies variability of ITS1 sequences in the ancient asexual Darwinula stevensoni (Crustacea: Ostracoda). Heredity, 87: 449-455.

Gandolfi, A., I.R. Sanders, V. Rossi \& P. Menozzi. 2003. Evidence of recombination in putative ancient asexuals. Mol. Biol. Evol., 20: 754-761.

Gandolfi, A., E.B.A. Todeschi, V. Rossi \& P. Menozzi. 2001b. Life history traits in Darwinula stevensoni (Crustacea, Ostracoda) from Southern European populations under controlled conditions and their relationship with genetic features. J. Limnol., 60: 1-10.

Gandolfi, A., E.B.A. Todeschi, K. Van Doninck, V. Rossi \& P. Menozzi. 2001c. Salinity tolerance of Darwinula stevensoni (Crustacea, Ostracoda). Ital. J. Zool., 68: 61-67.

Ghetti, P.F. \& K.G. McKenzie. 1981. Ostracodi (Crustacea, Ostracoda). Guide per il riconoscimento delle specie animali delle acque interne italiane. C.N.R. AQ/1/108, 11: 83 pp.

Harsham L.G., A.A. Hoffmann \& A.G. Clark. 1999. Selection for starvation resistance in Drosophila melanogaster: physiological correlates, enzyme activities and multiple stress responses. J. Evol. Biol., 12: 370-379.

Havel, J.E. \& P.D.N. Hebert. 1989. Apomictic parthenogenesis and genetic diversity in Cypridopsis vidua (Ostracoda, Cyprididae). Heredity, 62: 383-392.

Havel, J.E. \& P.D.N. Hebert. 1993. Clonal diversity in parthenogenetic Ostracods. In: K.G. McKenzie \& P.J. Jones (Eds), Ostracoda in the earth and life sciences. A.A. Balkema, Rotterdam: 353-368.

Hoffmann, A.A. \& P.A. Parson. 1989. Selection for increased desiccation resistance in Drosophila melanogaster: additive genetic control and correlated responses for other stresses. Genetics, 122: 837-845.

Judson, O.P. \& B.B. Normark. 1996. Ancient asexual scandals. Trends Ecol. Evol., 11: 41-46.

Lampert, W. \& H. Brendelberger. 1996. Strategies of phenotypic low-food adaptation in Daphnia: filter screens, mesh sizes, and appendage beat rates. Limnol Oceanogr., 41: 216-223.

Martens, K. (Ed.). 1998. Sex and Parthenogenesis. Evolutionary ecology of reproductive modes in non-marine Ostracods. Backhuys Publishers, Leiden.

Martens, K., G. Rossetti \& D.J. Horne. 2003. How ancient are ancient asexuals? Phil. Trans. R. Soc. B, 270: 723-729. 
Mezquita, F., G. Tapia \& J.R. Roca. 1999. Ostracoda from springs on the eastern Iberian Peninsula: ecology, biogeography and palaeolimnologocal implications. Palaeogeogr. Palaeoclimatol. Palaeoecol., 148: 65-85.

Normark, B.B., O.P. Judson \& N.A. Moran. 2003. Genomic signatures of ancient asexuals lineages. Biol. J. Linn. Soc., 79: 69-84

Patarnello, T. \& B. Battaglia. 1992. Glucosephosphate isomerase and fitness: effects of temperature on genotype dependent mortality and enzyme activity in two species of the genus Gammarus (Crustacea: Amphipoda). Evolution, 46: 1568-1573.

Ranta, E. 1979. Population biology of Darwinula stevensoni (Crustacea, Ostracoda) in a oligotrophic lake. Anns zool. Fennici, 16: 8-35.

Ross, M.J., J.W. Curtsinger \& R.O. Megard. 1996. Development of population structure in Daphnia clones in a stratified lake. Heredity, 77: 292-302.

Rossi, V., A. Gandolfi, G. Gentile, W. Geiger \& P. Menozzi. (2004). Low genetic variability in the ancient asexual ostracod Darwinula stevensoni. Ital. J. Zool.: in press.

Rossi, V., I. Schön, R.K. Butlin \& P. Menozzi. 1998. Clonal genetic diversity. In: K. Martens (Ed.), Sex and Parthenogenesis: Evolutionary Ecology of Reproductive Modes in Non-Marine Ostracods. Backhuys Publ., Amsterdam: $257-$ 274.

Rossi, V., E.B.A. Todeschi, A. Gandolfi, M. Invidia \& P. Menozzi. 2002. Hypoxia and starvation tolerance in individuals from a riverine and lacustrine population of Darwinula stevensoni (Crustacea: Ostracoda). Arch. Hydrobiol., 154: 151-171.
Schön, I., R.K. Butlin, H.I. Griffiths \& K. Martens. 1998. Slow molecular evolution in an ancient asexual ostracod. Proc. R. Soc. Lond. B, 265: 235-242.

Schön I., A. Gandolfi, E. Di Masso, V. Rossi, H.I. Griffiths, K. Martens \& R.K. Butlin. 2000. Persistence of asexuality through mixed reproduction in Eucypris virens (Crustacea, Ostracoda). Heredity, 84: 161-169.

Stearns, S.C. 1987. Why sex evolved and the differences it makes. In: S.C. Stearns (Ed.), The evolution of sex and its consequences. Birkhauser Verlag, Basel: 15- 31 pp.

Swofford, D.L. \& R.B. Selander. 1981. BIOSYS-1: a Fortran program for the comprehensive analysis of electrophoretic data in population genetics and systematics. J. Hered., 72: 281-283.

Tatara, C.P., M. Mulvey \& M.C. Newman. 1999. Genetic and demographic responses of mosquitofish (Gambusia holbrooki) populations exposed to mercury for multiple generations. Environ. Toxicol. Chem., 12: 2840-2845.

Turgeon, J. \& P.D.N. Hebert. 1994. Evolutionary interaction between sexual and all-females taxa of Cyprinotus (Ostracoda: Cyprididae). Evolution, 48: 1855-1865.

Turgeon, J.\& P.D.N. Hebert. 1995. Genetic characterisation of breeding systems, ploidy levels and species boundaries in Cypricercus (Ostracoda). Heredity, 75: 561-570.

Weider, L.J. 1985. Spatial and temporal genetic heterogeneity in a natural Daphnia population. J. Plankton Res., 7: 101123.

Weider, L.J. \& P.D.N. Hebert. 1987. Ecological and physiological differentiation among low-Arctic clones of Daphnia pulex. Ecology, 68: 188-198.

Wuethrich, B. 1998. Why sex? Putting Theory to the test. Science, 281: 1990-1982. 